\title{
Complex Systems Approach and Critical Thinking in the Construction of the Research Project about the Youth in a "Marginalized" Community in Merida, Yucatan, Mexico
}

\author{
Ksenia Sidorova, Roxana Quiroz Carranza, Astrid Karina Rivero Pérez \\ Universidad Autónoma de Yucatán, México
}

\section{Introduction}

The paper discusses the construction of a collective research project focused on the analysis of the youth from a "marginalized" urban area. The subjects of the research are all students of a high school, created by a local university specifically for the needs of their community. We look into the processes of their construction as knowing subjects that possess their own ideas on what it means to be young, participate in personal networks, and have had a unique experience related to the human rights, which more than often are violated in the case of "marginalized" youth.

In the paper we discuss the very elaboration of the research object. Based on the constructivist paradigm of the systems approach of Rolando Garcia, our research has led us to make explicit our own standing on the empirical problem we have chosen and thus the epistemological and theoretical position we adopt to construct the research problem. The "parts" and the "processes" our system is made of are the product of our standing on the issue we analyse in the research. Adherents to the "epistemology of the south" of Boaventura De Sousa Santos and the critical perspective on culture and development of Esteban Krotz, we apply "alternative" concepts to "name" the empirical referents and serve of the complex systems thinking to reveal the "other" side of the urban area known as the "south" of Merida. Marginalized, poor and violent, according to the official and media discourse, in our research it also stands out as a context of social injustice, racism, and discrimination in which some young people have risen as subjects that have defied their life circumstances, and have constructed ideas of what the good life and happiness -a good, dignified, free, and happy life (as Krotz (2002 \& 2004) puts it)- would be like. This utopian horizon which the subjects aspire to reach its components, challenges, and strategies to make it closer- is something we try to 
make visible through the analysis of the three principal sub-categories that conform the three subsystems of the major system that our research delimits as its object.

\section{Epistemic Frame}

There are two approaches we have recurred to in order to construct the object of our research: the constructivist systems approach of Rolando Garcia and what might be called "critical thinking" approach as represented by Boaventura De Sousa Santos, Pablo Gonzalez Casanova, and Esteban Krotz.

\section{The constructivist systems approach}

As to the constructivist systems approach, we have parted from Rolando Garcia's assumption that "No system is given at the starting point of the research. The system is not defined but is definable. An adequate definition can only appear in the process of the very investigation" (Garcia, 2006, p. 39; free translation). We share Garcia's "antiempirist" view, according to which the system and its properties are not given and cannot be accessed through direct experience of a "neutral observer". On the other hand, our research project stems from a real-life problem we detect and then represent and construct through theoretical concepts as a knowledge problem to be treated and solved through the research process. Therefore, this research is empirical as far as the explanations we expect to give will only be acceptable if confirmed through empirical corroboration (see Garcia, 2006, p. 40).

The empirical elements which comprise the system to be constructed are called "observables" by Garcia. Their empirical character is given by their "material existence"; they are "out there". Nevertheless, what they are and how they behave and relate to one another and to the "whole" is something the researchers are to define based on the theories and concepts they have selected and defined to frame the system. Therefore, the "observables" are not "pure"; according to Garcia, they "suggest a previous construction of relations by the subject [the researcher]. They are charged with theory, they are data of experience that are already interpreted" (Garcia, 2006, p. 43; free translation). The role of the theory is to "turn intelligible the facts, organize them, establish hierarchies and explain them. Establish causal relationships between them" (Garcia, 2006, p. 46; free translation).

What is a complex system, then? According to Garcia, it is "a representation of the reality that is analysable as an organized totality in a sense that it has a specific functioning. The functioning as a set of activities that the system conducts or allows to conduct as a result of the coordination of the functions that its constituent parts perform. 
The non-decomposable and semi-decomposable systems are complex systems given they imply interdefinable elements or sub-systems" (Garcia, 2000, p. 68; free translation). The system we construct in our research project is a semi-decomposable complex system.

\section{Critical thinking: making the system's contradictions visible and making the silenced voices audible in the search of an alternative view of well-being and happiness}

The necessity to recur to complex systems thinking has been recognized by some Latin American social thinkers that denounce the current state of order in their countries, characterized by social, political, economical, and cultural inequality and injustice. In the search for alternatives to the current state of things they have recurred to different strategies. One of them has been to reveal the contradictions implicit in the functioning of the capitalist system as a historical formation; another has implied the analysis of the dominated groups that have been struggling for better life conditions, social equality, and justice: their ideas, actions, interactions, social movements, and projects. Yet another -and more recent strategy- has been the use of the complex systems approach which has been recognized as a means to maintain the dominant social system, but also -when used critically- as a powerful tool for social change. The common point where the critical thinking and the systems thinking meet is the recognition of the society as dialectics between the individuals and the social totality/whole where "the constant is the emergence of new realities" (Mejia Navarrete, 2008, p. 3; free translation). While the more conservative scholars are looking for the ways to guarantee a more optimal functioning of the dominant system, the critical thinkers are searching for a change, for the ways of making new realities emerge. They look at the present state of the system as "a possibility among possibilities", in Ilya Prigogine's terms (in Mejia Navarrete, 2008, p. 3). So then, what critical thinking scholars pretend to construct is knowledge that would serve as "a comprehension of possible alternatives" (Mejia Navarrete, 2008, p. 3; free translation). According to Mejia Navarrete, "To study the society is to recognize its creative possibilities" (2008, p. 3; free translation).

Based on these ideas, we adopt a critical approach and look at the reality we pretend to comprehend and explain as a complex system which is not a "functionally organized whole", but a "contradictory dialectical whole" (Gonzalez Casanova, 2005). This "contradictory dialectical whole", according to Gonzalez Casanova, is comprised of interacting parts -“dominant", "dominated", and "alternative" (as a possibility/ not given yet, the probability of which we want to explore).

Behind this taxonomy lies the author's critical stance on the present state of the world system which he defines as characterized by domination, depredation, and capitalist accumulation. He is worried about the lack of real inclusion of the alternatives 
to these processes and the system itself as the object of theorizing and reflection of what he calls "complexity sciences and techno sciences". Gonzalez Casanova asks the following question: "What is the meaning of the new sciences for the forces that struggle for an alternative world?" (2005, p. 283; free translation). In a search for a possible answer, he makes reference to auto regulated, adaptive, autopoietic dominant systems and the alopoietic dominated systems whose relations are interdefinable. The author states that: "The dominant systems redefine the dominated ones and the latter redefine the former, in the process of the mutual redefinition of their internal and external relations. These redefinitions or restructurations occur between dialectics and dialogues, conflicts and consensus, confrontations and negotiations, breakdowns and agreements" (Gonzalez Casanova, 2005, p. 290; free translation). This way we can talk about contradictory dialectical relations.

According to the author, one of the characteristics of the dominant systems is that they can perform creative changes in the production and domination relations with the objective of preserving or restoring their own stability. They are capable of constructing alternatives that allow them to readapt themselves, maintain, and even strengthen their force (Gonzalez Casanova, 2005, p. 295), as well as combine autopoietic and alopoietic relations to redefine conflicts and consensus (Gonzalez Casanova, 2005, p. 296).

The author notes that the systems approach gives primordial importance to the autonomy of thinking and acting of the complex dominant organizations, nevertheless he stands that the dominated organizations and actors also strive for autonomy. The efforts to reach major autonomy are very important as far as their objective is the reconfiguration of the currently alopoietic dominated systems which also implies the reconfiguration of the relations between the dominant autopoietic and the dominated alopoietic systems that at the present stage are clearly unequal. The seeds of the "alternativity" or the possibility of a new alternative system to the established one, characterized by unequal power relations -those of domination of one component towards the other- are seen by Gonzalez Casanova precisely in the actions and relations that the dominated organizations and subjects carry on in the fringes of the dominant system, and in mutual cooperation with other dominated organizations and actors that strive for a social change.

In our research project, our principal interest lies within the "dominated" system and the possibility of a change, of an emergence of a new social reality, which would be more just and more inclusive. To understand what the possibilities for a change are, we look at the subjects who form part of a "dominated" system: a "marginalized" youth group, who at the moment of the research were students of a high school created to attend the educational necessities of the urban area they live in. We have parted from the idea that the marginalized groups have been "invisibilised" in the social research 
(De Sousa Santos, 2009). That is, they have been attributed a series of exogenous characteristics - violence, marginality, poverty, etcetera - by scholars, politicians, the media, but their own experiences and voices have been barely heard or listened to. None the less, these subjects "with their multiple random combinations, their uncertainties, contradictory conducts, and even illogical behaviour have an active role in the development of the real world" (Mejia Navarrete, 2008, p. 3, free translation). That is why it is important to explore their experience, projects, and the ideas of well-being that are not necessarily coincident with the dominant projects aimed at "developing" this social group. We concur with Mejia Navarrete who suggests that "the alternatives are the result of the limits created by the present actions of the social subjects themselves, from which the new paths are elected" (Mejia Navarrete, 2008, p. 3, free translation). We also concur with De Sousa Santos and his "epistemology of the south", which is aimed at making visible the "dominated" subjects and groups in their own terms and as capable of imagining and struggling for their own projects of a better life. We admit, with Krotz (2003), that each cultural group has created its own ideas of the good life and happiness, and in the search of a better life for everyone, it is our duty as social scholars to make visible and explore the viability of these "other" alternatives of wellbeing. Krotz says:
... all forms of culture and society that anthropological sciences study along the human history and in every place of the planet and in the complex present of our world, constitute an only history of search, an interminable history of search of the happy life, an attempt of a grundriss adequate to found an organization of a collective life that would be viable and, even more, able to be lived with dignity and liking by everyone. [It is] A search that is multiple and permanent, always started anew after failures, returns from the deadlocks, and at times even perversions, a search that combines what is generated inside [each culture and society] through the adoption of promising cultural traits that come from other parts - all that in order to give a possibility of the good life for all. Vida buena that at the same time is buena vida... (Krotz, 2003, p.39; free translation).

Finally, we admit, with Wallerstein, quoted by Mejia Navarrete, that the social knowledge implies values, that is, it is not neutral, and only this way it is true, good, and beautiful (Mejia Navarrete, 2008, p. 9). We agree that, as Gonzalez Casanova declares, "There is no truth without a standing" (2005, p. 105, free translation). Our standing on this project could be defined as "a search of new situations and creative possibilities of the human reality" (Mejia Navarrete, 2008, p. 8, free translation). We aspire to build knowledge in a "bottom up" manner (from the inside of the "dominated" system), through a collective research project, minimizing pre-constructed categories and theories, in a search of the situated emergent phenomena, making visible what has been -or has been made- invisible. 


\section{Representation of the contradictory dialectical system delimited in the research project}

In our research project we are studying a group of young people from a marginalized urban area, in the south of Merida, who have managed to finish an innovative high school created by a local university. We look at them as active subjects in a context characterized by poverty, discrimination, and social injustice, and we inquire into the possibilities of a better life -a good, dignified, free, and happy life (Krotz, 2002 \& 2004)- for this social group. What does it mean to live well for these young people? What elements of a good life are already present in their lives and their community? What elements are inexistent? What mechanisms make it possible or impossible to make a good life more viable in the context represented by a middle sized city -and in particular, one of its most segregated areas- where these young people live? The system we have constructed to respond these questions is as follows:

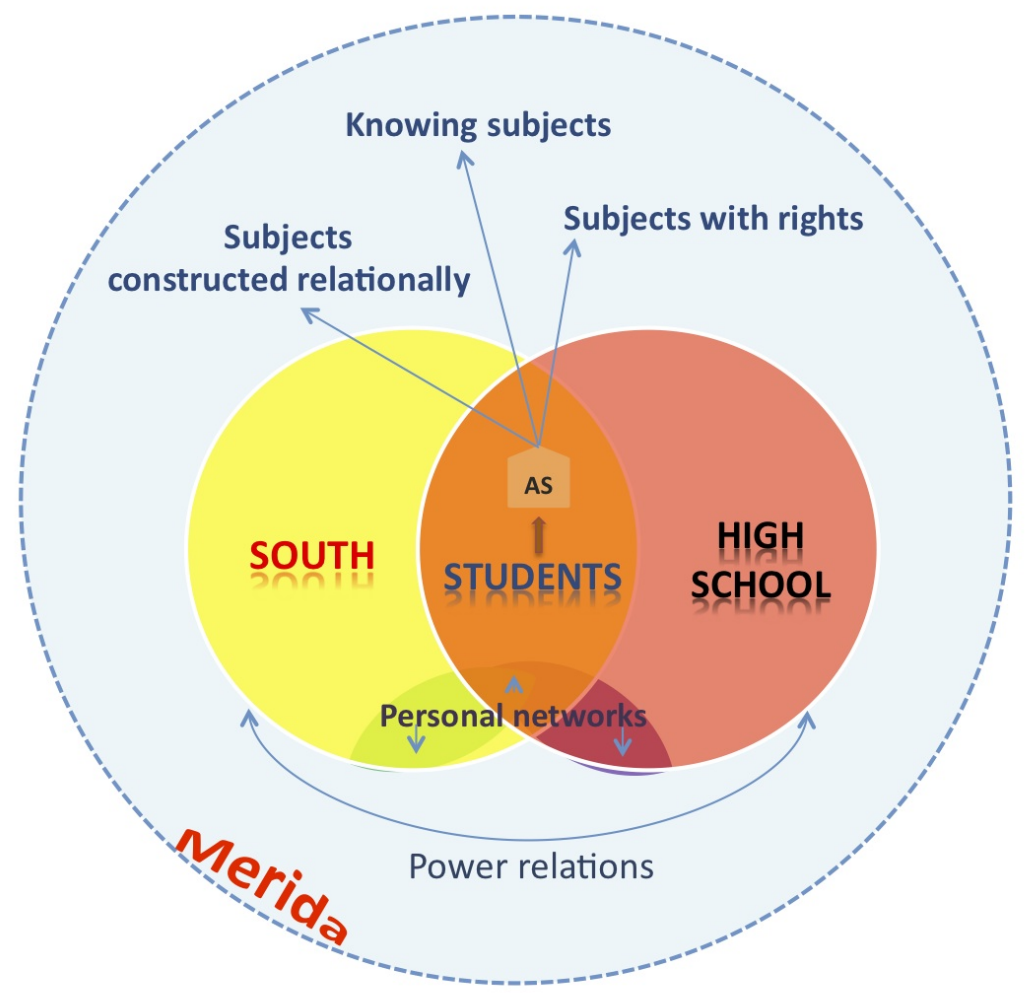

Figure 1. Representation of the contradictory dialectical system of the research project 
The system is delimited by the very frontiers of Merida, the capital city of the state of Yucatan, to the south east of Mexico. ${ }^{1}$ In terms of the contradictory dialectical system constructed, Merida is not only a geographical referent; it is also a social, economic, political, and more importantly, symbolic referent. First of all, it represents a context of segregation and social exclusion. The transformations that the city has experienced since the end of the nineteenth century to the present time have derived into a scheme of a socioeconomic distribution of its population that corresponds to the following pattern: the north is rich, the south is poor, the east and the west are the middle class areas.

The south of Merida (the dominated system) concentrates the greatest number of popular and marginalized settlings (colonias and fraccionamientos) ${ }^{2}$ It is an area of the greatest demographical density, lower economic resources, fewer and deficient public services, parks, and sports facilities. This area has received flows of migrant population from rural parts of the Yucatan Peninsula, including population of Maya origin, and other federative entities. It is a node of environmental contamination, limited job and educational opportunities, among other problems. We can also find there groups of population of different levels of poverty, including extreme poverty.

\footnotetext{
${ }^{1}$ According to the XIII Census of Population and Housing 2010 (XIII Censo de Población y Vivienda 2010), which was conducted by the National Institute of Statistics, Geography, and Informatics (INEGI, 2011), Merida has 830732 inhabitants, while the state of Yucatan counts with the total of 1955577 people. This means that Merida concentrates $42.48 \%$ of the total population of the state. The juvenile population of Merida, which comprises young men and women between 15 and 29 years old, comes up to 229282 inhabitants, that is the $27 \%$ of the Merida's population.

${ }^{2}$ It is also possible to differentiate between the "south" and the "deep south" (see Figure 2). The latter is the area of still greater poverty and marginality.

Journal of Sociocybernetics 11 (2013), pp. 25 - 45 


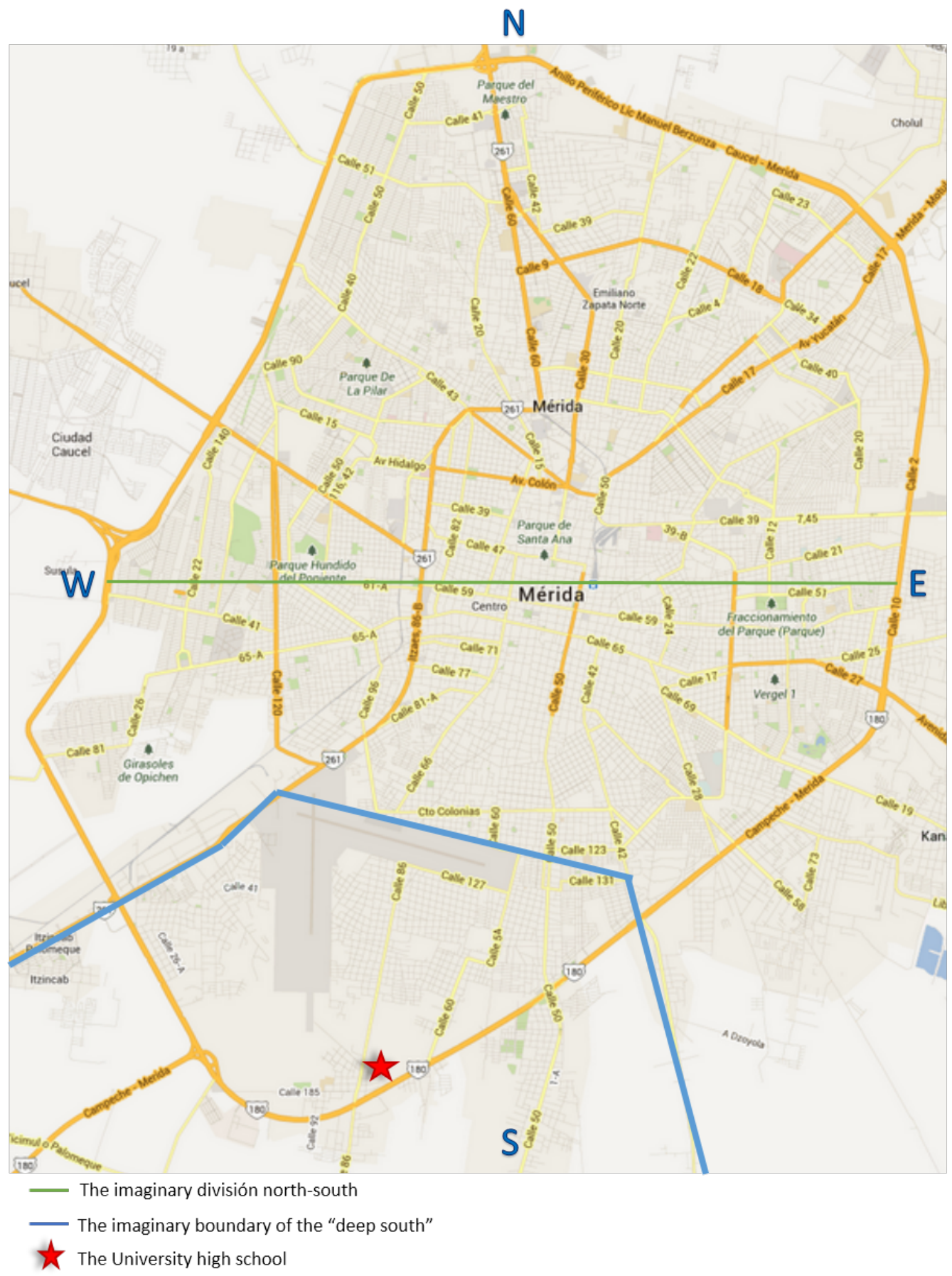

Source: Proper elaboration based on Google maps

Figure 2. City of Merida, Yucatan, Mexico 
Social inequality permeates all the aspects of everyday life of the population of the south of Merida. This inequality in all spheres of their life leads to discriminatory practices and social disadvantages that are expressed not only in a marked economic, social, cultural, ethnic, and territorial differentiation between those who possess sufficient resources and those who lack them, but also in a differentiated access to justice and the guarantees/ respect of human rights. This way, the socioeconomic characteristics of the south of Merida have turned it into an area with a pronounced negative stigma (produced by the dominant system).

The south of Merida has been the object of exogenous development projects (on the part of the dominant system). The population's participation in these projects has been limited. Among the probable reasons for that we can mention the fact that the projects tend to ignore the local knowledge and the cultural richness of the population that inhabits the area, many of them of Maya origin. Another reason is a strong tendency of "paternalism" and "assistentialism" that have been the strategies of the organizations that work in this area.

The high school that a local university has set up in the extreme south of the south of Merida is one of the projects that is aimed at solving the educational necessities of the youth that lives there. It has an objective to give quality education to this social group and promotes social projects aimed to contribute to the solution of different types of social and economic problems the local community faces. It is impossible not to mention the existence of power relations between the local community and the high school, since the vision, the educational program, and the organization of the educational process of the latter, are all designed from "above", without participation of the community itself. The educational program is different from that of other high schools of this university, that are located in other -less "problematic"- urban areas. Even so, the program has been designed as is thought/ imagined -by the people (university and school authorities) from outside the "south"-it would be useful to the young people from an area which is characterized primarily by its problems and needs, not by what its population already possesses, for example, cultural knowledge and practices. One of the first signs of "something going wrong" has been the fact that only 35 students of the initial group of almost 200, that comprised the first generation, managed to finish it. This has been attributed to their lack of study habits, lack of motivation, the fact that some belonged to street gangs, and so on. The drop out rate has reduced drastically in the new generations who are seen as more motivated and interested in studying. The educational process -the system of classes, assignments, projects, and grading- has been re-adjusted as well.

As to the high school students themselves, we have represented them as situated in the intersection of the dominant and the dominated system, although they belong to the 
latter one. They possess some of the characteristics of the population of south of Merida, including some cultural knowledge and practices, although they also have differences, as the decision they have taken to continue their education no matter what. Here we can see that they are eager to integrate into a dominant project and participate in it to the end, but, as the research has shown, they also resist it and denounce or question some aspects of their school that they consider discriminatory or even as violation of their human rights.

Now then, as Gonzalez Casanova (2005) suggests, each category we construct must be treated as a subsystem of the major system. The centre of our research is the category of youth in the south of Merida, and our research subjects are the students of the high school project we have just described. This major category is comprised of other three subcategories, which are the objects of the three individual projects that form part of the collective research project. The three subcategories -which we see as interdefinable parts of a semi-decomposable system and describe in the next section of the paper- are: students as subjects with rights, students as knowing subjects, and students as subjects constructed relationally. We stand that the analysis of the three sub-systems and their mutual relations will allow us, in the final integration phase of the research, build the representation of the present state and the possibilities of a "good life" project for this social group. Good life seen as an alternative way of thinking, acting, and being, which is not a part of the dominant system ideal of well-being, nor is it a part of the real-life conditions of the population that conforms of the dominated system, but is a utopian horizon that is imagined and aspired by the people, and if reached -in its totality or partially- will form part of an alternative system.

It is relevant to mention that the methodology we have applied in this research project has been mainly qualitative, including conversations with students and teachers, open-ended qualitative interviews, and participant observation. We have recurred to statistical data to characterize the area, its population, the state of the human rights in the case of the youth, etcetera.

\section{High school students from a marginalized urban area as subjects with rights}

The first subsystem can be called "The youth and the human rights" (see Figure 3). Its major category is young people as subjects with rights. According to Valenzuela Arce, young people are "one of the major excluded groups from the civil rights" (Valenzuela Arce, 2000, p. 207; free translation). The author argues that, generally speaking, this group has been defined as "peripheral and without proper rights" and has been labelled by the dominant institutions as "social subjects that lack rights". 


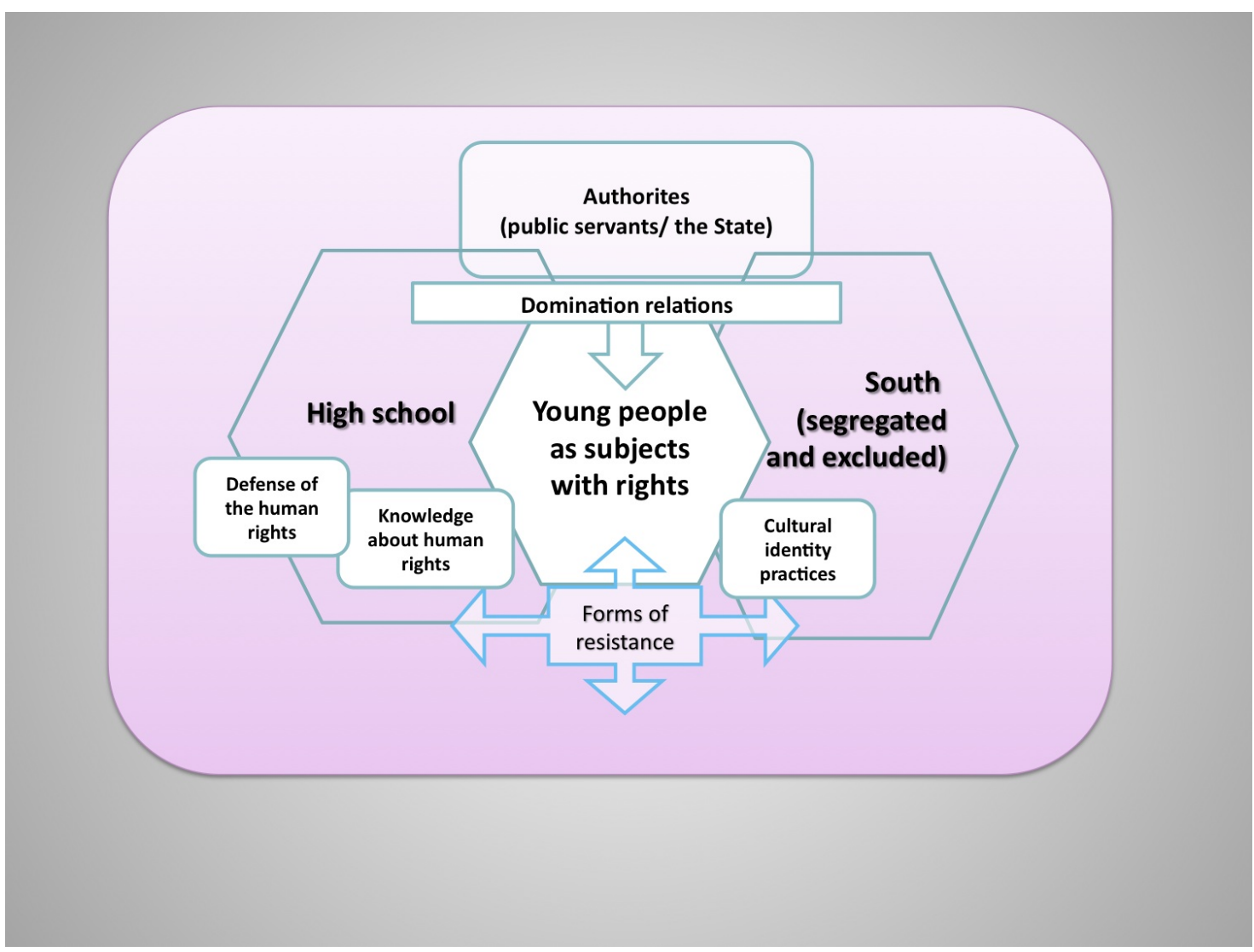

Figure 3. Representation of the subsystem "The youth and the human rights"

As part of the dominated system, the young men and women in the south of Merida experience constant violation of their rights because they are young, poor, and inhabit a segregated, marginalized, and stigmatized urban area. Among the rights that the dominant system fails to guarantee are: access to quality education, integral healthcare system, decent work, social and political participation, public manifestation of their identities, freedom of expression and meeting, freedom to create based on their cultural diversity, the use of free time, freedom of election of their partner, and the responsible exercise of their sexuality. The dominant system has collocated these young people in a situation of vulnerability, which is made more poignant because of the criminality that is imputed to them, since, according to the authority and the media, poor and marginalized young people are the main protagonists of insecurity (Meneses Reyes, 2008).

There are different types of authority in the dominant system that frequently take repressive actions against these young people. Repression is more frequent when the 
young people express their cultural and youth identities and practices, through the clothes they wear, the way they spend free time with their peers in public places, some of the forms of organization, such as "gangs", and so on. It is possible to affirm that the young people that live in the south of Merida "as the effect of economic inequality and social stratification are practically excluded from the supposed rights that have been legitimized for their integration and development, driving them into a situation of a still greater marginality and poverty" (Meneses Reyes, 2008, p. 153; free translation).

The contradictory dialectical relations between the dominant system and the dominated one, cultural identities and practices of these young people, as well as the knowledge (of their rights) they have acquired in high school, that they try to put in practice in their everyday life to defend their human rights, can be recognized as forms of resistance, seeds of "alternativity" (alternatividad). When they make visible certain expressions of their distinctive cultural identities and practices, which they express through graffiti, some forms of meetings and parties in their neighborhoods, and so on, they turn into a serious problem for adult institutions, to which they are subordinated economically, judicially, and morally (Urteaga, 2005). As they claim their human rights, they become a menace to the social system.

As we recognize that the young people are subjects with rights, we critically admit that the institutional and universal discourse on human rights is a manifestation of creative changes that the dominant system has managed to realize in order to preserve and reestablish its proper stability (Gonzalez Casanova, 2005). At the same time, the appropriation of their rights by the young people as a strategy of resistance-one of the many other resistance actions that have taken place all over the world-, turns them into a first-order recourse that these young men and women can recur to in order to reach a life that would be good, dignified, free, and happy (Krotz, $2002 \& 2003$ ).

\section{High school students as knowing subjects}

The central category of the second subsystem is that of students as knowing subjects (see Figure 4). On the macro level we can observe that there is a contradiction between the multicultural reality of the Yucatan Peninsular -almost $30 \%$ of its population is Maya speaking and many more recognize themselves as belonging to this culture- and the dominant project/ paradigm of development which does not recognize the true dialogue between different forms of knowledge, in particular, the scientific knowledge and local knowledge, including that of Maya culture. This situation is called "cognitive injustice" by De Sousa Santos (2009). Inside the dominant system, which officially recognizes that Mexico is a multicultural state and in fact has official programs of intercultural education, there is a contradiction since it does not include elements of its multiple cultures into its development paradigm. 
On the intermediate level, we find two major elements: the high school and the students' personal networks. The high school has been founded by a local university to attend a specific group of students. The teachers define them by their social and economic characteristics, but tend to minimize the role of their cultural characteristics. Nevertheless, the majority of students have parents or other close relatives that speak Maya or have this cultural origin. This does not seem to be of major importance to the formal educational process. For example, the university and its high schools have established Spanish and English as official languages, even though Maya is the language of an important part of population in Yucatan, including the south of Merida. In general terms, according to the teachers, the students can succeed if they finish school and enter the university.

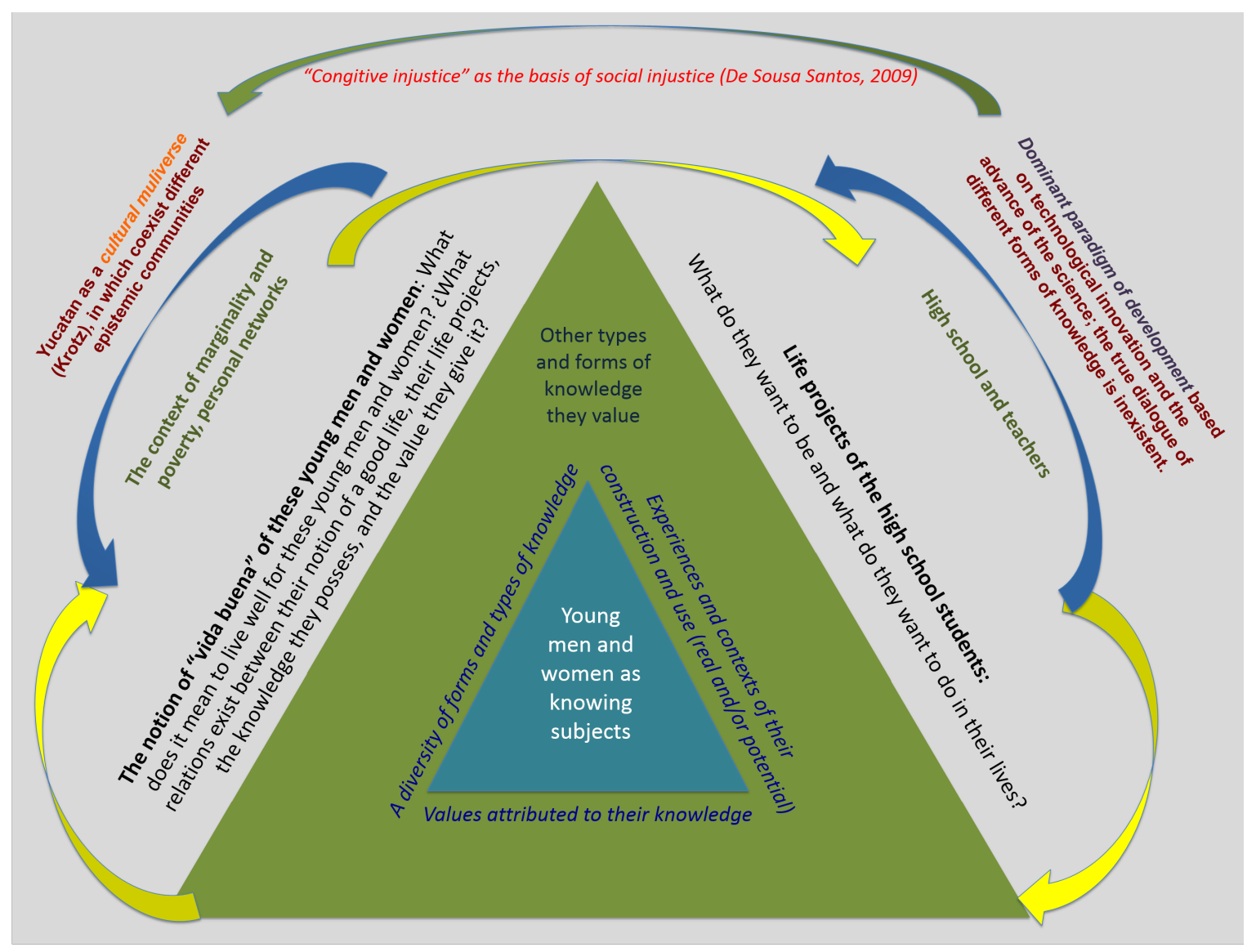

Figure 4. Representation of the subsystem "The young men and women as knowing subjects" 
As to the students' networks, they are object of the next project. Even so, it is relevant to mention at this point some internal contradictions of this dominated subsystem: the students' parents "prefer" not to teach them Maya; they pass some of the cultural knowledge they have, but they bet on the high school and university education as the key to their sons and daughters' success.

On the micro level, the level of the subjects themselves, the young people have proved to be bearers of multiple forms and types of knowledge of different origins, which they combine and employ in their everyday life (at home, in church, at work, in the neighbourhood, at school). They attribute different values to their knowledge, tending to believe that thanks to the knowledge they acquired in their families they have grown as responsible and autonomous/ independent individuals. Even so, it is school knowledge that will give them possibility to advance in their lives.

On the other hand, while school and university are seen as keys to success, the major elements of the idea of a good life are family, friends, and lack of social and economic problems. To achieve it, the professional university knowledge will be necessary. It is seen by the students as useful to help the community and the family, and as a source of a better income, which in turn can help solve family problems and make students' personal dreams, as travelling and seeing the world, come true. Cultural knowledge plays minor role in the life projects of these young people, which reflects the contradiction inside the dominated system, since its proper cultural elements are devaluated by their own bearers. Even so, some young people are aware of the richness of their cultural elements, and if it were viable, they would make use of them. Given the established state of things, it is not so viable, though, and they know it.

\section{High school students as subjects constructed relationally}

In this subsystem (see Figure 5) the young people are seen as a "relational construction of juvenile actors with the agents of their immediate social contexts (adults, young people, and children) and the agents of farther but present contexts" (James \& Prout en Urteaga, 2011, p. 151; free translation). To comprehend the students it is necessary to recognize that they were born and have grown in specific sociocultural contexts, that is, it is necessary to contextualize them through their family, work, religious and other relations (Saucedo, 2007). These relations are studied through personal networks, since the youth is understood as a relational construction, that is, as constructed through interaction with others (Mascareño, 2000). 


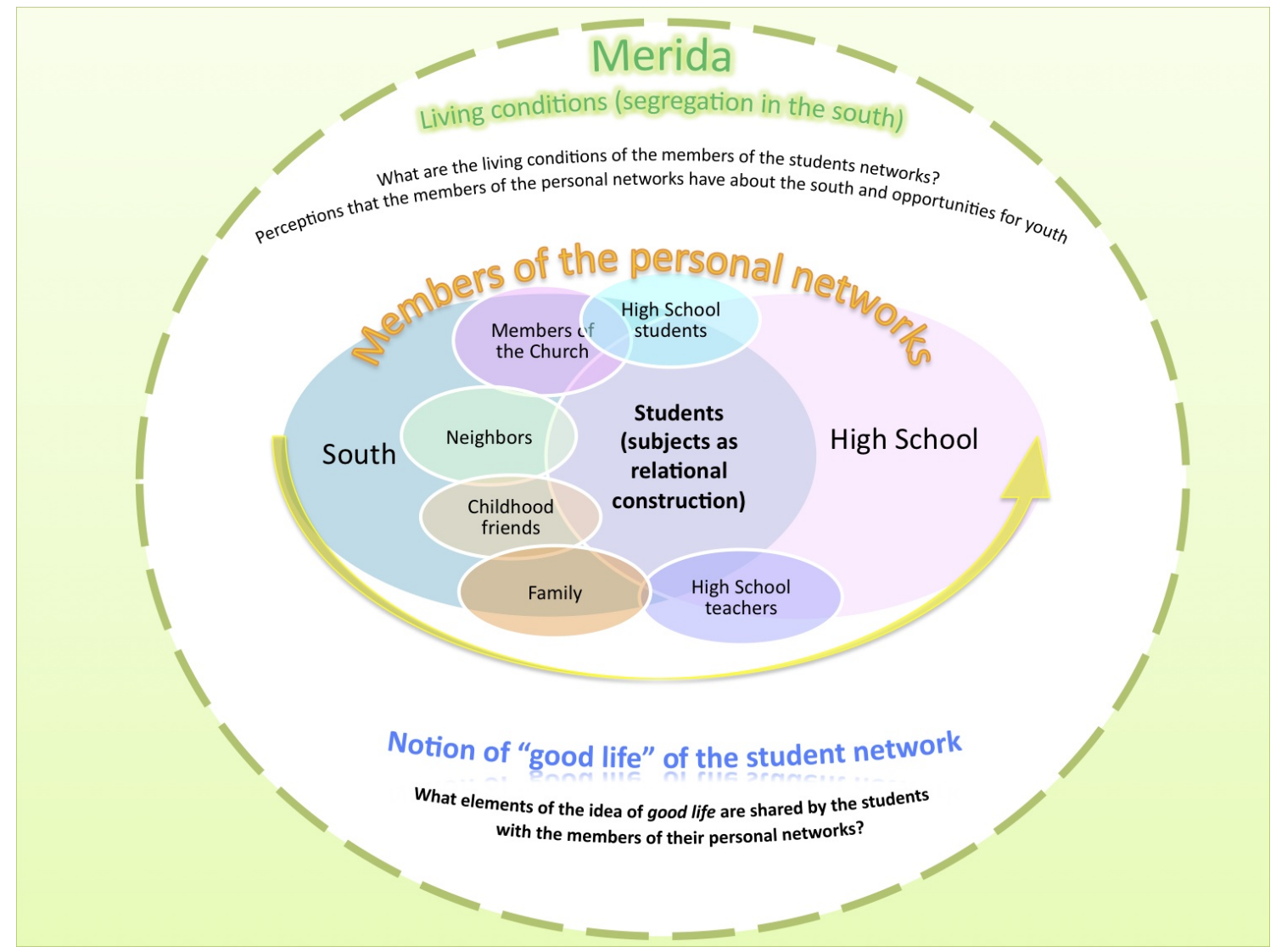

Figure 5. Representation of the subsystem "The young people as a relational construction"

In the case of the research subjects, we have observed that some members of personal networks adopt discourses and practices of the dominant system, which construct them as poor, marginalized, violent and/or „without future“. Their representations of their life conditions and opportunities for a good life also contain elements of the dominant system, as well as proper constructions.

In the case of the teachers who form part of the students' personal networks, on the one hand, there is a pronounced interest in helping students en their educational process; nevertheless, sometimes the teachers describe them as different from other students they had worked with before. They stress that the young people come from the families that face numerous problems, such as economic needs, alcoholism, depression, separation conflicts, divorce, and domestic violence. Some teachers still possess negative stereotypes of the urban community the students come from. Other teachers, though, are critical of the high school educational program because it is different form that of other 
high schools of the university, which are not situated in the south of Merida. They recognize that the educational project is oriented to stereotyped young people.

School plays a pivotal role in the discourse of the students' family members as a way to obtain a better life as well; some of them mention that the university has done a "great job" by setting up the school and giving quality education to the young people of this urban area. Nevertheless, they also recognize that in their previous educational process the young people have had multiple disadvantages, which make it more difficult for them to study and meet the standards of their high school. In their turn, the inhabitants of "the south", members of social networks of the young people, have generated survival strategies that are different from those generated by the State, among them the formal education. Some of the endogenous strategies are self employment, including informal commerce, mutual support networks, through which people help neighbours and friends to get informal work, etcetera.

Among the students' families there is tension inside the very notion of "the south" as a viable place to live, its shortcomings and needs. On the one hand, they define "the south" as their home, recognize close relations with different family members and the existent of support they receive from their neighbours. On the other hand, they reproduce the sigma of the south as an area of vandalism, poverty, and insecurity. This way, the discourses of the members of the students' personal networks present a tension of exogenous and endogenous/ proper elements. The way the members of the networks are solving the tension -on their own or accompanied by other institutional or personal actors- is an important element of analysis, because it constitutes one of the factors that can widen the possibilities to construct an alternative way of living, or that will only allow to reproduce the established scheme of existence.

\section{In search of a good life: elements, mechanisms, and possibilities of an alternative system}

At the present stage of our research, which is still underway, we can observe there are elements and mechanisms present in the dominated system that make it possible to imagine/ think of the possibilities of an alternative system model:

1. In the case of the young people we have worked with, there is a marked sensibility/ awareness of social problems, great awareness of social justice and injustice, as well as knowledge of the human rights that the students occasionally try to put into practice to defend their rights. This knowledge and the correct proceedings as to how to put it into practice should be promoted by teachers that work with the students and other social actors (human rights organizations) that are not in direct contact with students at this moment but who could help them apply the knowledge they have and claim their rights. It is 
difficult to achieve that, though, if the authority is not eager to help make these attempts possible/ viable instead of blocking them.

2. The young people we have worked with are bearers of multiple forms and types of knowledge, including school knowledge and local cultural knowledge, that are unevenly valued. It is important to recognize, make visible, revalorize, and keep transmitting (particularly en the case of the Maya culture) all these different types of knowledge in order to put them in dialogue and in practice in search of better life opportunities for the inhabitants of the south of Merida. It is difficult to achieve that, though, if the authority does not give full recognition and include other -other than scientific- forms of knowledge and life experiences as valid part of educational schemes and/or other strategies aimed at searching for better life opportunities for everyone.

3. There are extended operating social networks in the south of Merida, which are sources of solidarity and mutual support. It is possible to promote even more organized forms of cooperation between these people based on the cooperative forms of interaction that are already there. It is also important to stimulate the transmission of proper/ local culture, which has been devaluated - by the others, the media, and the very inhabitants of the south - in the real everyday life. It is hard to achieve this, though, if the authority keeps seeing these forms of social and economic interaction and organization as peripheral, informal, or simply irrelevant.

What we discover behind these three blocks of issues that are present but are made invisible or are seen as of little relevance in the case of the subjects of our study is quite interesting, since in fact we are facing the three elements that the Mexican philosopher Luis Villoro (2007) has declared as the three major challenges of "the society to come" (see Figure 6). The first one is justice understood as non-exclusion. According to Villoro, social exclusion is indicative of the existence of social injustice, the recognition of which should be the first step in the path to justice in any culture and in any context. The second challenge is democracy -and more specifically, community democracy-, which is characterized by reciprocity and non-domination. The domination relations are a real life property of the existent social order, where the real-life recognition of the other and of the common good is flawed. The third one is intercultural co-existence to be manifested in the plural State (not only as a discourse, but as real everyday practice, politically and legally founded). The cultures are multiple but there is no real recognition of plurality, instead the relations between the cultures tend to be those of unicultural imposition, not dialogue. The lack of the reciprocity that is, in fact, behind all the three challenges manifests itself in the dominant-dominated relations that 
Gonzalez Casanova denounces in the case of the present world system and that are to be reconfigured as an exigency of an alternative social order.

We find, in other words, that some young subjects in the south of Merida who, in the dominant system's terms, are marginal and poor; in the terms of our search of the forms and opportunities for a better life, are also solidary, interconnected, recognize cultural diversity, possess cultural knowledge, some of which is rooted to Maya culture, as well as have a sense of social justice. These characteristics are not universally extended in the south of Merida, nor are they shared by all young people who live there. Nevertheless, they are present and constitute the seeds of an alternative better life model. One of the strategies to start exploring the path to make it closer and more viable is by including the three elements as the nodes of attention by the authorities and teachers of the high school itself (for example, through their community social projects).

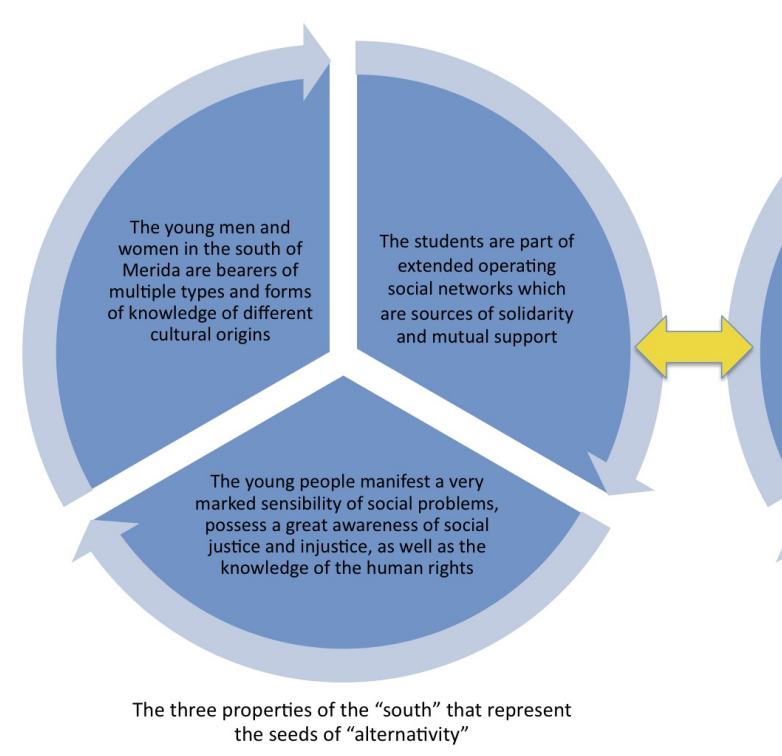

Figure 6. In search of a good life: elements of an alternative system

We are also aware that we lack other elements which could help us understand the possibilities of a social change in the south of Merida, which are, firstly, the processes that occur in the dominant system in relation to the three aspects we have explored and which are emerging as the result of the research. This information could allow us to 
look deeper into the relations - power relations - and tensions between the dominant and the dominated system on each of these issues. In other words, the research has suggested us new paths to a more holistic exploration of the "problem" of the south of Merida and its youth which, as we have shown, is an area of extraordinary opportunities that are rooted into the very organization, social experience, and proper culture of these people, traditionally marginalized, criminalized, and stereotyped by the official institutions and media discourse. The appropriation of this discourse - which has turned into the common sense shared by the people in the south and outside it - has been one of the stumbling blocks that makes the search for a better life harder, since it does not allow the people to stand up as knowing social actors with rights. The social knowledge we generate tries to make a difference and re-configure the existent representations of the social reality we study, and together with them, the reality itself which is inseparable from the knowledge that describes it and that can be used as a tool for its further transformation, in the search of a life that will be good for everyone.

\section{References}

De Sousa Santos, B. (2009). Una epistemología del Sur. México: Siglo XXI Editores.

Fuentes Gómez, J. H. (2005). Espacios, actores, prácticas e imaginarios urbanos en Mérida, Yucatán, México. Mérida, México: Ediciones de la Universidad Autónoma de Yucatán.

García, R. (2006). Sistemas complejos. Conceptos, método y fundamentación epistemológica de la investigación interdisciplinaria. Barcelona: Gedisa.

García, R. (2000). El conocimiento en construcción. Barcelona: Gedisa.

García Gómez, C. (2007). La conformación urbana de Mérida. In García Gómez, C. \& Bolio Arceo, E. (Coord.). Autoproducción de vivienda en Mérida. Zonas urbanas en proceso de consolidación. (p. 155-172). Mérida, Yucatán: UADY.

González Casanova, P. (2005). Las Nuevas Ciencias y las Humanidades: De la Academia a la Política. Barcelona: Anthropos; México: Instituto de Investigaciones Sociales (UNAM).

Instituto Nacional de Estadística, Geografía e Informática (2011). XIII Censo de Población y Vivienda 2010. México: INEGI. Retrieved January 15, 2013, from http://www.inegi.org.mx

Krotz, E. (2004). Diálogos interculturales en la Península de Yucatán: perspectivas para las relaciones entre la sociedad maya y la no maya. In Temas Antropológicos, 26(1-2), 22-54.

Krotz, E. (2003). El multiverso cultural como laboratorio de vida feliz. In Alteridades, $13(25), 35-44$. 
Krotz, E. (2002). Sociedades, conflictos, cultura y derecho desde una perspectiva antropológica. In Krotz, E. (Ed.). Antropología jurídica: perspectivas socioculturales en el estudio del derecho. (pp. 13-49) México: UAM-I/ Anthropos.

Lugo Pérez, J., Tzuc Canché, L., Guzmán Medina,V., Barredo Baqueiro, G., Caballero Solís, L., Macedonio Hernández, C., Torres Rivero, J., Campo Marín, T., Carrillo Trujillo, C. \& Castillo León, T. (2012). Diagnóstico para la intervención social en dos colonias del sur de Mérida: San Antonio X'Luch III y San Luis Sur Dzununcán. Informe final del proyecto de investigación aplicada, clave SISTPROY PSIC-2011-0008. Mérida, Yucatán: Programa Juventud y Sociedad de la Universidad Autónoma de Yucatán.

Mascareño, C. (2000). Redes Sociales Territorializadas. Nuevos Espacios para la Política Social Alusión al Caso Venezolano. Retrieved december 6, 2012, from http://www.clad.org.ve/anale6/mascared.html

Mejia Navarrtete, J. (2008). Epistemología de la Investigación Social en América Latina. Desarrollos en el siglo XXI. Cinta Moebio, 31, 1-13. Retrieved june 10, 2013, from http://www.moebio.uchile.cl/31/mejia.htm

Meneses Reyes, M. (2008). Juventud, espacio urbano y exclusión social. In Cordera R., Ramírez Kuri, P., Ziccardi, A., (Coord.). Pobreza, desigualdad y exclusión social en la ciudad del siglo XXI. (pp. 153-167). México, D.F.: Siglo XXI Editores.

Pérez Medina, S. (2010). Segregación, recreación y calidad de vida en Mérida. México: UNAM/ Coordinación de Humanidades/ Programa Universitario de Estudios sobre la Ciudad/ Programa de Maestría y Doctorado en Urbanismo.

Reyes Domínguez, G. (2003). Carnaval en Mérida. Fiesta, espectáculo y ritual. Ciudad de México-Mérida, Yucatán: Instituto Nacional de Antropología e Historia/ Universidad Autónoma de Yucatán.

Saucedo Ramos, C. (2007). La importancia de la escuela en las experiencias de vida de los estudiantes: su valoración retrospectiva a través de relatos de vida. In Guzmán Gómez, C. y Saucedo Ramos, C. (Coords). La voz de los estudiantes. Experiencias en torno a la escuela. (pp. 23-43). México: Ediciones Pomares/ CRIM/ UNAM.

Valenzuela Arce, J. M. (2000). "Tránsitos" peligrosos. La violación de los derechos humanos de los jóvenes y los migrantes. In Bernardo Bátiz, J. A., Colorado García, G. (Coords.). Los derechos humanos y los retos del nuevo milenio. (pp. 207-232) México: Instituto de Investigaciones de la H. Cámara de Diputados / Instituto Tecnológico y de Estudios Superiores de Occidente.

Villoro, L. (2007). Los retos de la sociedad por venir. México: Fondo de Cultura Económica.

Urteaga Castro-Pozo, Maritza (2005). Los debates teóricos desde la perspectiva sociocultural sobre los derechos de las y los jóvenes. In "Iniciativas para la Identidad y la Inclusión" y "Elige. Red de Jóvenes por los Derechos Sexuales y reproductivos", pp. 1-39. Retrieved january, 2011, from http://www.inicia.org/public/Maritza_Urteaga.pdf 
Urteaga, Maritza (2011). La construcción juvenil de la realidad. Jóvenes mexicanos contemporáneos. México: Universidad Autónoma Metropolitana/ Juan Pablos Editor. 